\title{
A MEMÓRIA FANTASMAGÓRICA EM $O$ HOMEM DA AREIA, DE E. T. A. HOFFMANN: UMA LEITURA À LUZ DO BERGSONISMO DE GILLES DELEUZE
}

\author{
Juliana Oliveira do Couto \\ Doutoranda em Letras - Teoria da Literatura e Literatura Comparada - pela \\ Universidade do Estado do Rio de Janeiro (UERJ) \\ juliana.ocouto@gmail.com
}

\section{RESUMO}

A memória pode ser reavivada sob distintos vieses. Ao resgatarmos uma lembrança em forma de imagem, presentificamos esta recordação, gerando uma "imagem-lembrança", de acordo com o conceito de Henri Bergson (1859-1941), resgatado por Gilles Deleuze (1925-1995) em seu estudo intitulado Bergsonismo (1987). A lembrança presentificada se encontra fortemente presente na rememoração de eventos traumáticos, suscitando uma fixação da imagem aterradora, o que ocorre no conto de E. T. A. Hoffmann (1776-1822) O Homem da Areia (1816), no qual esta lembrança se converte em um fator fantasmagórico. $O$ presente trabalho analisa, desse modo, a forma como o princípio bersgsoniano de "imagem-lembrança", investigado a partir da publicação deleuziana, se manifesta no texto hoffmanniano, perpassando a problemática da fantasmagoria.

Palavras-chave: imagem-lembrança, fantasmagórico, E. T. A. Hoffmann, Bergson, Deleuze.

\section{ABSTRACT}

Memory can be revived under countless aspects. By recovering a remembrance in the shape of an image we presentify this recollection, originating an "recollectionimage", according to Henri Bergson's (1859-1941) concept, revived by Gilles Deleuze (1925-1995) in his book entitled Bergsonism (1987). The presentified recollection is strongly present in the remembrance of traumatic events, inciting a fixation of the frightful image, which happens in E. T. A. Hoffmann's (17761822) short story The Sandman (1816), in which this recollection becomes a phantasmagorical factor. The aim of the present paper is, therefore, to analyze the way that the Bergsonian principle of "recollection-image", investigated from Deleuze's work, manifests in Hoffmann's text, passing by the matter of phantasmagory.

Keywords:

recollection-image, phantasmagorical, E. T. A. Hoffmann, Bergson, Deleuze. 
O aspecto fantasmagórico da existência e das percepções humanas perpassa uma série de textos literários modernos e encontra terreno profícuo especialmente no Romantismo alemão, período no qual Ernst Theodor Wilhelm Hoffmann (1776-1822) - o terceiro nome foi alterado para Amadeus em homenagem a Mozart - publica os seus escritos, que apresentam um mundo real entrecortado por mundos mágicos ou horripilantes.

Na obra O Homem da Areia (1816), em especial, Hoffmann explora os limites entre realidade e delírio, introduzindo à narrativa uma visão fantasmagórica de elementos, à primeira vista, banais. Este terror ante o ordinário e até mesmo ante o familiar calca-se em uma memória aterradora, que figura como espécie de gatilho à fantasmagoria. É justamente neste aspecto que o conto hoffmanniano e a filosofia de Bergson se encontram: a lembrança imagética, que presentifica o passado, se apresenta como o fio que conduz toda a narrativa d' O Homem da Areia.

O presente trabalho destina-se, portanto, a examinar o conto de Hoffmann especialmente sob a perspectiva bergsoniana da "imagem-lembrança". Vale destacar que a teoria de Henri Bersgon (1859-1941) será trabalhada indiretamente, ou seja, a base teórica deste estudo está presente no Bergsonismo, de autoria de Gilles Deleuze (19251995). Cabe salientar ainda que, de modo a tecer uma análise abrangente, o presente estudo partirá de uma contextualização da escrita de Hoffmann para, somente então, introduzir os pontos de contato entre $\mathrm{O}$ Homem da Areia e a filosofia bergsoniana.

No que se refere à produção de Hoffmann, esta encontra-se em consonância com a exploração dos "lados noturnos da existência humana" (BEUTIN, 1993, p. 292), característica do Romantismo tardio alemão. A cisão do eu - que remete aos conflitos 
entre o burguês racional e metódico e o artista explorador das raias da loucura - dá o tom à sua escrita permeada pela fantasmagoria. De acordo com Carpeaux,

[Hoffmann] foi o mais completo temperamento de artista em toda a história da literatura alemã - não Ihe faltava a boemia, com as bebedeiras intermináveis que alegava necessárias para obter as alucinações que depois transformou em histórias de espectros. Esse artista completo foi burocrata do serviço público prussiano, depois juiz: burocrata pontualíssimo e juiz íntegro. Essa ambiguidade, esse estar em casa em dois mundos é a fonte de sua imaginação poética (CARPEAUX, 2013. p. 108-9).

A convergência entre consciente e inconsciente e entre realidade e imaginação não se limitavam, portanto, à obra hoffmanniana: o autor fez de sua própria vida uma reflexão sobre as fronteiras da existência e o papel do artista ante o mundo, questão tão cara aos alemães em diversos momentos históricos. É justamente através desta reflexão que a obra de Hoffmann se destaca na última fase romântica: se, em fins do século XVIII, o diálogo entre a Revolução Francesa e a agitação intelectual na Alemanha se faziam presente nos círculos literários, o início do século XIX se viu assombrado pelos excessos da emblemática revolução política ocorrida no país vizinho e suas consequências. Entra em cena, então, um mundo sombrio, demoníaco:

Tal como o final do século XVIII foi marcado pela experiência da Revolução Francesa, o início do século XIX foi determinado pela Restauração. A esperança numa realização política dos postulados "liberdade" e "igualdade" fora duplamente iludida: através do regresso da França à monarquia e do sucesso da restauração europeia em geral, relacionado com a mesma, bem como das contradições que se foram manifestando de forma cada vez mais óbvia no decurso da evolução burguesacapitalista. A alienação era a reacção [sic] predominante à evolução restauracionista e às oposições vividas. A atmosfera de entusiasmo da primeira fase do romantismo 
deu lugar a uma visão sombria, sarcástica e cindida da situação (BEUTIN, 1993, p. 291).

Vale salientar que não somente Hoffmann, mas outros românticos de peso, deram voz à problemática da alienação e aos mundos horripilantes, como Adalbert von Chamisso (1781-1838) com seu A história maravilhosa de Peter Schlehmil (1814) - o homem que vende sua sombra - e o Da vida de um imprestável (1826), de Joseph Freiherr von Eichendorff (1788-1857), cujo protagonista se lança rumo a uma peregrinação a fim de se distanciar de uma vida alienada.

Retomando a temática da exploração das fronteiras entre tangível e intangível, cabe destacar que o pensamento de Hoffmann afinava-se com a ideia corrente entre os românticos que postulava o caráter efêmero e superficial da realidade, em oposição à qualidade perene do mundo sobrenatural, sendo aquela um mero aspecto banal da existência e este o verdadeiro mundo - característica do idealismo alemão'. Para atingir esta perenidade, seria necessário mergulhar nas profundezas da alma, onde o universo sombrio e a atmosfera mágica se encontram. Estaria aí a essência da tarefa do artista:

Para os românticos alemães a realidade empírica é mera aparência; no âmago, por trás e além dos fenômenos físico-materiais, o mundo é espírito - e o espírito facilmente se condensa em "espíritos". A criatividade imaginativa do gênio e poeta, sobrepondo-se às categorias do senso comum da burguesia filistéia [sic]; a fantasia, o sonho, certos estados de loucura, suspendendo a lógica diurna e o encadeamento normal dos chamados fatos, facilitam o contato com a verdadeira essência do universo. Espaço e tempo, a lei de causa e efeito, todos os recursos da nossa mente para entender e dominar os processos físicos da natureza, não têm validade absoluta (ROSENFELD, 1993, p. 29-30). 
A negação da previsibilidade e superficialidade do cotidiano burguês era contraposta, portanto, a um mundo mágico, revelado somente aos iniciados no caráter transcendente da vivência; este sim, essencial. O mundo prosaico tornou-se, desse modo, ponto central do material romântico em sua fase tardia, possuindo a finalidade de "trazer ao insípido cotidiano o perfume da transcendência" (VOLUBUEF, 1999, p. 118). Vale enfatizar ainda que é justamente nesta abordagem que reside a questão da automação do homem. Entraremos em maiores detalhes acerca desta problemática oportunamente.

No que concerne à memória imagética, lê-se, logo no primeiro capítulo do Bergsonismo, que as lembranças "ligam os instantes uns aos outros e intercalam o passado no presente" (DELEUZE, 2012, p. 20), ou seja, ao acessarmos nossas lembranças, o passado é presentificado, vindo à tona como imagem. Não é sem razão que o passado se impõe com tanta veemência ao presente, afinal o presente passa a todo o momento e somente o que permanece é o passado: "é do presente que é preciso dizer, a cada instante, que ele 'era' e, do passado, é preciso dizer que ele 'é', que ele é eternamente, o tempo todo" (ibidem, p. 46). Esta imposição do passado sobre o presente torna-se mais clara através da oposição entre os conceitos de "atualidade" e "virtualidade": aquela se configura como presença, enquanto esta é caracterizada como esquecimento. Os fatos dos quais não há recordação permanecem em nossa memória de modo nebuloso, amorfo, ao passo que as lembranças que podem ser acessadas são transformadas em "atualidade" ao trazê-las para o presente, ou seja, tornam-se "imagens-lembrança" (ibidem, p. 54).

Cabe frisar que, na configuração bergsoniana da memória, há uma coexistência entre passado e presente, que melhor pode ser visualizada através da emblemática "metáfora do cone": “O passado não só coexiste com o presente que ele foi, mas - como 
ele se conserva em si (ao passo que o presente passa) - é o passado inteiro, integral, é todo o nosso passado que coexiste com cada presente" (ibidem, p. 50 - grifado no original). Em outras palavras: a memória poderia ser caracterizada como um cone invertido, no qual distintos níveis de virtualidade - o passado - estão armazenados - o presente está localizado na base, no segmento mais afunilado deste cone. O elemento que distingue estes níveis de virtualidade é o grau de contração ou distensão destas camadas. Ao acessar lembranças e trazê-las à atualidade, a memória passa, desse modo, por um processo de instalação no passado.

Direcionando o estudo de Bergson/Deleuze a uma leitura d' O Homem da Areia, é possível perceber a forte presença da memória imagética nas falas e ações do protagonista Natanael. Aqui a supremacia do passado é nítida no que se refere ao trauma provocado pelo seu algoz de infância Coppelius/Homem da Areia. Transpondo a intriga a termos bergsonianos, pode-se afirmar que a lembrança do pavoroso "amigo" do pai de Natanael é tornada atualidade a partir de um gatilho disparado em sua fase adulta e, deste momento em diante, jamais retorna à virtualidade. São pontuais as frases do tipo "desde então, a imagem do Homem da Areia ficou gravada em meu espírito com cores atrozes" (HOFFMANN, 2010, p. 18) ou "as feições de Coppelius estão impressas indelevelmente em minha memória" (Ibidem, p. 30). A memória de Natanael deixa de simplesmente acessar lembranças para agir no presente, conforme postula a teoria bergsoniana, e reverte-se em fonte de tormento ao reviver uma figura traumática, o que é desencadeado a partir da visão de Coppola, um vendedor de barômetros, responsável por suscitar a lembrança de Coppelius e o terror do protagonista em sua fase adulta. E é com extremo pavor que Natanael confessa seu estado de espírito a seu amigo Lothar ao descrever o encontro com a horrenda figura: 
Se - pelo menos - você estivesse aqui, poderia ver com seus próprios olhos. Mas, tenho certeza, vai pensar que sou um louco visionário. Para ser breve: a pavorosa visão que tive, e cuja fatal influência tento em vão descartar, consiste simplesmente em ter visto - no dia 30 de outubro, ao meio-dia - um vendedor de barômetros, que entrou em meu quarto e me ofereceu seus instrumentos. [...]

Você pode imaginar: unicamente circunstâncias muito particulares - e que me marcaram bem lá por dentro - poderiam ter feito com que esse pequeno acontecimento tenha se tornado importante (Ibidem, p. 14-5).

É a partir deste momento da narrativa que as lembranças aterrorizantes de Natanael acerca do advogado Coppelius, "parceiro profissional" de seu paii", são pintadas com cores vívidas e conduzem o leitor rumo a um enredo pleno de fortes referências imagéticas. É digno de nota o fato de haver aqui um entrecruzamento de dois passados: a imagem de Coppola, o carrasco do pequeno Natanael, e o encontro com Coppelius, gatilho do aterramento do protagonista em sua fase adulta - terror que é tornado nítido através do minucioso detalhamento da data na qual o evento se dá. Entrecortam-se, portanto, uma lembrança recente e uma lembrança antiga, provando a singular acessibilidade da memória a eventos passados - seja um passado que ocorreu há poucos dias ou há décadas -, o que justifica a coexistência entre passado e presente via níveis de virtualidade. Conforme ressaltado anteriormente, o passado não deixa de existir, ou seja, sempre "é". Natanael mergulha em sua virtualidade e resgata uma imagem que há muito não povoava sua mente, o que atesta a intensa presença deste passado.

De acordo com Deleuze, ao atualizarmos o virtual "um apelo parte do presente, de acordo com exigências ou necessidades da situação presente" (DELEUZE, 2012, p. 53), isto é, um evento presente exige o resgate de uma lembrança para que a reação adequada a uma ação que nos é imposta possa se concretizar. Esta se configura como a função 
prática da memória, ou seja, o uso da memória em prol de uma ação no mundo. No caso de Natanael, esta invocação do passado não é prática, mas debilitante. Deleuze aponta a debilitação do plano mental de outro modo, a partir de uma "perturbação mecânica do esquema motor", no qual o acesso às lembranças é prejudicado com tal severidade, de modo que atividades simples deixam de ser possíveis, o que ocorre com portadores de alzheimer, por exemplo - o filósofo cita a afasia como exemplificação (Ibidem, pp. 58-9). O protagonista hoffmanniano, ao contrário, sofre de um excesso de lembranças ou de uma presentificação aterradora do passado. De modo diverso de um portador de alzheimer, Natanael torna-se incapaz de viver uma vida funcional a partir da presença insistente de uma lembrança traumática, não via ausência de lembranças ou inacessibilidade a estas reminiscências iii. É nesta imposição aterradora do passado que o fantasmagórico se revela.

A presença do fantasmagórico no conto hoffmanniano se manifesta na figura de Coppelius/Coppola, o que desencadeia um processo delirante na mente de Natanael, onde tangibilidade e devaneio se interpenetram. Este processo é iniciado no primeiro encontro com Coppola, descrito anteriormente, e se desenrola até o trágico término da narrativa, com a morte do protagonista em pleno delírio. Observa-se, desse modo, uma influência do fantasmagórico no plano do real, ou seja, o contato com a própria realidade torna-se aterrador, afinal, Coppola não é apenas um delírio de Natanael, mas uma figura real que desencadeia um movimento alucinatório na mente do protagonista. É neste aspecto que entra em cena o que Anatol Rosenfeld chama de "aniquilamento fantasmagórico da realidade externa": 
Na obra de Hoffmann o aniquilamento fantasmagórico da realidade externa se produz constantemente, quer pela passagem a um mundo ideal, quer pela deformação grotesca da própria realidade-ambiente. Os bons e maus espíritos de um mundo transcendente, onírico e espectral, repetem e ecoam a fragmentação e a desarmonia do mundo real. Mas o que na realidade se apresenta difuso, indeciso e comprometido pela falta de definição, adquire, quando projetado para o plano mágico da essência, uma força, expressividade e violência inadvertidas. É uma verdadeira luta entre anjos e demônios que então se trava (ROSENFELD, 1993, p. 30 - grifos nossos).

No caso d' O Homem da Areia, este aniquilamento se dá através da interpenetração entre a realidade empírica e um mundo horripilante, isto é, Natanael enxerga o mundo real através da lente da fantasmagoria. Não é por acaso que o entorpecimento ao qual o protagonista é submetido inicia-se justamente ao olhar através das lentes da luneta adquirida pelas mãos de Coppola. O próprio Natanael reconhece haver pagado caro demais pela luneta, mas não previa que este valor alto não se referia somente a questões monetárias:

Antes de sair do quarto, Coppola olhou Natanael de soslaio. Olhar estranho, debochado - e desceu rindo as escadas. Bem, pensou Natanael, está rindo de mim. Acho que paguei caro por esta luneta, muito caro. Enquanto pensava, teve a impressão de ouvir um estertor profundo reboar pelo quarto, sinistramente. Mas tinha sido ele mesmo que suspirara (HOFFFMANN, 2010, p. 62 - grifos nossos).

Inicia-se, então, de modo definitivo o terror de Natanael: a princípio surge um entorpecimento - que o impede de distinguir o caráter automático de Olímpia, por exemplo -, que culmina em um profundo e horripilante delírio, responsável por sua morte. 
Retomando a questão do papel do olho no contexto da obra hoffmaniana, é de suma importância destacar sua essencialidade no conto, afinal, é justamente neste órgão que as imagens são formadas e, posteriormente, retidas na memória e resgatadas em forma de imagens-lembrança. Conforme evidenciado acima, o olho de Natanael, que vê através da luneta de Coppola, configura-se como a porta de entrada a um mundo alucinatório, no qual real e ilusório coexistem. E é precisamente este caráter simbólico do olho que é perseguido por Coppelius/Coppola em sua obsessão pelo autômato perfeito.

Cabe frisar que a presença de um autômato em um enredo literário não surge em Hoffmann como um fato isolado, pelo contrário, faz parte de um movimento de rejeição a uma vida apática e maquinal, característico da fase tardia do Romantismo alemão, conforme salientado anteriormente. Estas "máquinas humanas" entram em cena de forma a contrapor vivacidade a uma mera aparência de vitalidade. Conforme destaca Karin Volubuef,

[...] o ritmo diário dos filisteus - dado ser tão maquinal e afeito ao automatismo deu margem a que [os românticos] introduzissem em suas obras figuras como marionetes, bonecas, autômatos (Pikulik, 1979, p. 164 e 283-5). Trata-se de figuras que ostentam uma aparência de vida quando na verdade são meros mecanismos artificiais, destituídos de sentimentos, de capacidade de pensar e julgar. $O$ encontro com essas figuras sempre é uma experiência marcada pelo horror, e a percepção do mundo como uma imensa máquina - na qual não há espaço para a sensibilidade do artista - redunda frequentemente [sic] em loucura, a exemplo do que ocorre nas páginas de $O$ homem da areia, de E. T. A. Hoffmann (VOLUBUEF, 1999, p. 117 -grifos nossos).

No conto hoffmanniano a automação surge em uma dicotomia que se estabelece no eixo Olímpia (autômato) versus Clara (noiva humana de Natanael), sendo que ambas 
entram em confronto com o protagonista por distintas razões: enquanto Clara contrapõe a obsessão horripilante de Natanael a sua forma racional de enxergar as questões do então namorado, Olímpia diverge de Natanael justamente por conta de seu caráter rígido, automático. Um importante fator que distingue as duas jovens e apresenta a vivacidade de Clara em oposição ao mecanicismo de Olímpia, reside na eloquência daquela ante a fala monossilábica desta. Enquanto a jovem autômato apenas reage maquinalmente às ações de Natanael, agradando-o por sua aparente total concordância com o rapaz - tudo o que a moça é capaz de dizer é “ah-ah-ah!" -, Clara busca argumentar racionalmente com um Natanael desvairado, apresentando possíveis justificativas à sua obsessão, sem apelar ao sobrenatural:

A exaltação mística repugnava o racionalismo de Clara, mas parecia inútil tentar refutá-la. Era necessário que Natanael tentasse demonstrar: Coppelius era o princípio do mal e tinha se apropriado dele, Natanael, no momento daquela espera atrás da cortina, e que o odiento demônio ainda perturbaria irremediavelmente a felicidade amorosa deles, para Clara, então, se tornar muito séria e dizer:

- Sim, Natanael, você tem razão. Coppelius é princípio maligno, princípio hostil. Pode fazer coisas horríveis, é potência diabólica que entrou em sua vida, mas apenas enquanto não o banir de seu espírito e de sua mente. Enquanto você acreditar nele, existirá e atuará. Todo o poder dele vem de sua crença nisso (HOFFMANN, 2010, p. 49).

A argumentação de Clara baseia-se nitidamente em um princípio que entra em confronto direto com o misticismo de Natanael: o jovem sofreria de uma perturbação provocada pela sua própria mente, tornando-o incapaz de evocar lembranças de modo a agir no mundo. Conforme ressaltado anteriormente, o entendimento de Natanael não mais possui um caráter funcional, mas delirante. O juízo do protagonista é de tal modo 
transtornado, a ponto de acusar Clara de automatismo, mas não enxergar o caráter maquinal de Olímpia. Ao refutar o poema que Natanael compõe de modo a extravasar a sua experiência horripilante, Clara é rejeitada de modo veemente:

- Natanael, meu bem-amado Natanael! Joga fora esse poema absurdo, demente, insensato!

Natanael dá um salto, indignado, e grita, empurrando Clara:

- Autômato maldito, sem vida! (ibidem, p. 54).

Vale salientar que a problemática do homem-máquina alude à concepção cartesiana de ser humano, segundo a qual o funcionamento do corpo humano seria análogo ao mecanismo de uma máquina perfeita. Este conceito é contestado por Bergson, que apresenta o fator hesitação ou intervalo - presente somente no ser vivo em oposição ao automatismo da máquina: “Entre os dois [estímulo e resposta], o cérebro estabelece um intervalo, um desvio, seja porque ele divide ao infinito o movimento recebido, seja porque ele o prolonga em uma pluralidade de reações possíveis" (DELEUZE, 2012, p. 19).

O homem, ao contrário da máquina, não responde imediatamente aos estímulos recebidos, mas hesita em um intervalo que se estabelece neste processo sensório-motor (ação-reação). O autômato, por sua vez, é preciso, imediato, objetivo. Não é sem razão que Olímpia, mesmo que monossilabicamente ou friamente, reage de imediato aos estímulos de Natanael: seja ao retribuir um beijo ou ao proferir seus "ah-ah-ah!" após as elucubrações do namorado.

Cabe destacar que, ao observar Olímpia mais atentamente pela primeira vez, Natanael percebe uma qualidade mecânica na jovem, mas, ao fixar seu olhar através da 
luneta de Coppola, entra em cena um entorpecimento provocado pelo olhar de Olímpia, a princípio visto como frio e sem vida:

Sem querer, olhou para o quarto de Spalanzani. Olímpia estava sentada, como sempre, defronte à mesinha, braços à frente, as mãos juntas. Só então Natanael repara nos traços admiráveis do rosto de Olímpia. Apenas os olhos the parecem estranhamente fixos, mortos. Mas como olhasse insistentemente para ela através da luneta imaginou que dos olhos de Olímpia se desprendessem vaporosos clarões lunares. Parecia que a vida voltava para eles, pois flamejavam cada vez mais vivamente, enquanto Natanael permanecia à janela, como se estivesse enfeitiçado, contemplando sem se cansar a beleza celestial de Olímpia (HOFFMANN, 2010, p. 61 grifos nossos).

A questão do olho/olhar assume a partir de então uma importância fundamental na narrativa, pois é exatamente através dos olhos de Olímpia que se dá o enfeitiçamento de Natanael, que passa a enxergar neles toda a vivacidade que a jovem possuía somente em sua impressão. A "beleza celestial" da moça alude ainda a uma atmosfera onírica, delirante. Não é sem razão, que é justamente no estado de sono que a capacidade prática e racional da consciência se vê enfraquecida, pois neste estado não há necessidade de acessar lembranças e recortar a realidade para agir ante uma situação empírica. Retomando o pensamento de Bergson, é possível observar, neste caso, que os distintos níveis de virtualidade se mesclam, já que lembranças desnecessárias à ação invadem a mente daquele que sonha.

Com efeito, que sucede a uma criatura que se contenta em sonhar? Sendo o sono como que uma situação presente, que só tem como exigência o repouso, nenhum outro interesse que o "desinteresse", tudo se passa como se a contração faltasse, 
como se a relação extremamente distendida da lembrança com o presente reproduzisse o mais distendido nível do próprio passado (DELEUZE, 2012, p. 57).

É nítida, portanto, a interpenetração entre passado e presente e entre atualidade e virtualidade. Natanael torna-se incapaz de distinguir realidade empírica de devaneio, intercruzando os elementos em todas as suas concepções, para sempre comprometidas sua "recuperação", como se sabe, é apenas aparente. É no fim da narrativa que o estado de sono/devaneio se mescla ao singular valor do olho/olhar: Natanael cai morto após um horrendo delírio provocado justamente pela luneta de Coppola, ao tentar apreciar a paisagem do alto de uma torre acompanhado de Clara, a quem, inconscientemente, tenta assassinar:

Natanael instintivamente põe a mão no bolso, saca a luneta de Coppola e a dirige para aquele ponto. Clara aparece enquadrada nas lentes. Súbito, uma convulsão contrai suas artérias e veias. Mortalmente pálido, via Clara, mas logo, torrentes de fogo ardem, cintilantes, em seus olhos desvairados. Urra!... Rugido horrível, de animal acuado. Depois, deu um salto no ar e grita com voz forte enquanto ria ameaçadoramente:

- Boneca de madeira, gira, gira! Boneca de madeira, gira!

Em seguida, agarrou Clara com violência - quer jogá-la no espaço -, mas Clara segura a balaustrada com mortal desespero, em seu pavor (HOFFMANN, 2010, p. 85 - grifos nossos).

\section{Considerações finais}

A problemática da perturbação do discernimento via fantasmagoria, bem como a questão da dicotomia homem versus máquina rende uma extensa discussão, que se 
ramifica em uma série de vertentes possíveis. Visando a economia do texto, optou-se aqui por analisar estas questões partindo de um recorte da filosofia bergsoniana examinada indiretamente através do estudo de Deleuze.

Ademais, o conceito bergsoniano de "imagem-lembrança" vai ao encontro da narrativa hoffmanniana, permeada por devaneios e concepções distorcidas, nas quais o real se converte em horripilante através das lentes do fantasmagórico. As noções de "virtualidade" e "atualidade" vêm, ainda, enriquecer a discussão, pois o conto de Hoffmann calca-se em um aspecto fantasmático suscitado justamente por lembranças que retornam em forma de imagem, o que provoca a perturbação do protagonista.

Por fim, a interação entre ser humano e autômato, desencadeadora do horripilante, arremata uma trama povoada por um mundo real aberto ao sobrenatural, onde as concepções do protagonista tomam um caráter onírico, no qual a relação entre atualidade e virtualidade é completamente desfigurada.

O presente artigo propôs-se, portanto, a apresentar uma leitura bergsoniana/deleuziana das problemáticas trazidas à tona na literatura de Hoffmann, não sem antes partir de um panorama acerca do contexto no qual a obra veio a lume. Vale salientar que o estudo aqui exposto não esgota, de modo algum, as matérias abordadas, apenas aponta uma de suas inúmeras nuances. É possível concluir, por conseguinte, que o Romantismo tardio alemão guarda, ao menos no que se refere à obra de Hoffmann, íntimas afinidades com a filosofia de Bergson, apresentada ao mundo cerca de um século após a produção hoffmanniana.

\section{Referências}


BEUTIN, Wolfgang et al. História da literatura alemã: das origens à atualidade. Tradução de Anabela Mendes, Fernanda Gomes, Manuela R. Sanches, Maria Assunção P. Correia e Teresa Cadete. Lisboa: Cosmos, 1993. v. 1.

CARPEAUX, Otto Maria. A história concisa da literatura alemã. São Paulo: Faro Editorial, 2013.

DELEUZE, Gilles. Bergsonismo. Tradução de Luiz B. L. Orlandi. São Paulo: Editora 34, 2012. HOFFMANN, E.T.A. O Homem da Areia. Tradução de Ary Quintella. Rio de Janeiro: Rocco Jovens Leitores, 2010.

ROSENFELD, Anatol. Letras germânicas. São Paulo: Perspectiva: Editora da Universidade de São Paulo; Campinas, SP: Editora da Universidade Estadual de Campinas, 1993.

VOLOBUEF, Karin. Frestas e arestas: a prosa de ficção do Romantismo na Alemanha e no Brasil. São Paulo: Fundação Editora da UNESP (FEU), 1999.

\footnotetext{
' Visando a economia do texto, não entraremos em detalhes no que se refere a possíveis distinções ou pontos de contato entre a filosofia idealista e a bergsoniana. Este momento do presente estudo destina-se meramente a apresentar as condições históricas e literárias do período no qual a obra hoffmanniana veio a lume.

"A relação entre Coppelius e o pai de Natanael reflete a associação demoníaca entre Fausto e Mefistófeles. No período no qual O Homem da Areia veio a lume (1816), o Fausto I de Goethe já havia sido publicado há quase dez anos (1808). A história original data do século XVI (de autoria desconhecida).

iii Esta problemática suscita a questão acerca do que teria desparecido na mente em processo de degeneração: ou as lembranças em si se perdem ou apenas o acesso a estas lembranças torna-se vedado ao indivíduo (DELEUZE, 2012, p. 58-9). Não entraremos em maiores detalhes no que se refere a esta discussão a fim de não incorrer em desvio da proposta inicial do presente estudo.
}

Recebido em 9 de fevereiro de 2018.

Aceito em 23 de março de 2018. 